\title{
Design and Performance Analysis of Effective Controllers for Multi-level DC to DC Cascaded Boost Converter
}

\author{
Saktheeswaran RADHAKRISHNAN*, Murali DURAISAMY
}

\begin{abstract}
In this article, an investigation of effective controllers for Multi-level DC to DC Positive Output Cascaded Boost Converter operating in continuous conduction mode is carried out. The positive output cascaded boost converter is recently designed converter which increases the output voltage in geometric progression with simple structure and has better voltage transfer gain in comparison with conventional converter. In this study, two level cascaded positive output boost converter (TLCPOBC) using super lift technique was considered and the results were compared with single level cascaded positive output boost converter (SLCPOBC) to show the importance and need of Multilevel converters in DC to DC applications. Due to switching mode operation, the characteristics of TLCPOBC were non-linear in nature. In addition, during line and load variations, the system was not stable and converters behaved drastically. Therefore, an effective controller is essential to enhance the dynamic characteristics of converter. Linear controllers like Proportional Integral Controller (PI) and Proportional plus Proportional Integral Controller (P plus PI) were considered in this study. Here, PI controller acts as Single Loop Controller (SLC) whereas, P plus PI acts as Multi Loop Controller (MLC). The main advantage of MLC over SLC is that it may regulate both output voltage and inductor current of TLCPOBC which improves the performance of the system over a wide range of operating conditions. Using Ziegler -Nicholas tuning method, the parameters of controllers were obtained by the state-space equations of TLCPOBC. The performance of controllers is verified in MATLAB/Simulink models and results are validated to show the importance of an effective controller for TLCPOBC.
\end{abstract}

Keywords: DC to DC Power conversion; MATLAB/Simulink; Multi Loop Controller; State-space average model; Two Level Cascaded Boost Converter

\section{INTRODUCTION}

DC-DC converter plays a vital role in day to day life applications such as renewable energy, hybrid vehicles, battery charging, electric traction, fuel cell energy conversion system [1-6]. Many DC-DC converter topologies have been developed for these applications such as buck, boost, buck-boost, SEPIC, KY converters and Luo-converters (LCs) [7-9]. But any converter need good output voltage regulation, fewer ripples in the output voltage and reduced current and voltage stress. The recently designed DC-DC converter was Luo converter, which has Voltage Lift, Super Lift and Ultra Lift techniques [10]. DC to DC converters using Voltage Lift (VL) technique have been successfully employed in many applications. However, in VL technique, the output voltage of converter increases in arithmetic progression. But, Super Lift (SL) technique increases the output voltage in geometric progression and also effectively enhances the voltage transfer gain in power series. The Luo converter using SL technique was classified into POSLLC and NOSLLC. Even though Super Lift (SL) technique increases the output voltage in geometric progression the circuits are a bit complex. Hence, cascaded boost converter has been developed which enhances the output voltage in geometric progression with simpler structure using power law. To differentiate this converter from existing (VL) and (SL) techniques, these converters are entitled as cascaded positive output boost converters (CPOBC) and cascaded negative output boost converters (CNOPC). In this article, TLCPOBC using super lift technique was considered. The controller design was a challenging one for these Luo Converters. Therefore, in this paper both single loop and multi loop controllers were designed and the results were validated to show the importance of MLC for two-level cascaded positive output boost converter (TLCPOBC).

The control of a cascaded boost converter using single active switch was reported in [11]. However, the verification was not carried out for different operating conditions. POCBC has been well reported in [12].
Nevertheless, the efficiency of the same converter was around $78 \%$ and ripples were not considered in the study. PI controller based boost converter using parallel connection is reported in [13]. However, the ripples with this controller have produced $0.02 \mathrm{~V}$. In addition, the verification was not carried out for different line and load variation. DC-DC double boost converter using small signal modelling analysis has been discussed in [14]. But, the result analysis part has not been clearly carried out. DCDC boost converter using various controlling techniques has been well reported in [15-17]. But the controller has produced large peak overshoot around $45 \%$ with settling time of $0.06 \mathrm{~s}$. In addition, it has large output voltage ripples and voltage dip in output during line variations. Multi-stage DC-DC converters for PV applications have been well executed in [18]. But, only the simulation study was achieved for the designed converter. Design of Dual loop controller for boost converter is presented in [19]. In this paper, simulation analysis for different operating conditions has been carried out with SMC, PI and SMC plus PI. But, the output of these controllers has produced overshoots of $10 \mathrm{~V}, 15 \mathrm{~V}, 3 \mathrm{~V}$ with large settling time of $0.1 \mathrm{~s}, 0.025 \mathrm{~s}, 0.02 \mathrm{~s}$ respectively.

From the literature part it is clear that DC-DC converters using different linear controllers were carried out using single loop controller (SLC). However, for TLCPOBC using multi loop controller (MLC) under different operating conditions in continuous conduction mode (CCM) has not been carried out. Therefore, in this article TLCPOBC using multi loop controller (MLC) was designed and results were compared with single loop controller (SLC).

\section{WORKING OF CASCADED POSITIVE OUTPUT BOOST CONVERTER}

Cascaded boost converters effectively enhance the output voltage in geometric progression with simpler structure. It increases the voltage transfer gain using power law. These converters have several sub series namely main 
series, additional series, double series, triple series and multiple series. In this study, the main series was considered. The main series consists of single level cascaded positive output boost converter (SLCPOBC), two level cascaded positive output boost converter (TLCPOBC).

\subsection{Single Level Cascaded Positive Output Boost Converter}

The power circuit consists of single switch $S$, inductor $L_{1}$, capacitor $C_{1} \&$ diode $D_{1}$. When the switch $S$ is turned on, the input voltage $V_{\text {in }}$ appears across inductor $L_{1}$ and output voltage $V_{\mathrm{o}}$ appears across capacitor $C_{1}$. Similarly, when switch is turned off, the inductor current $i_{L 2}$ declines with $-\left(V_{0}-V_{\text {in }}\right)$.

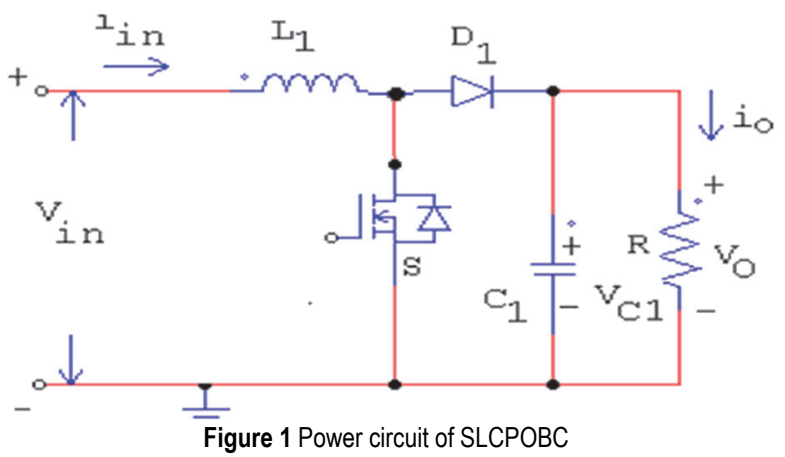

Therefore, the output voltage $\left(V_{0}\right)$ and output voltage transfer gain of SLCPOBC can be written as Eq. (1):

$$
\begin{aligned}
& V_{\mathrm{o}}=\frac{1}{(1-k)} V_{\text {in }} \\
& G=\frac{V_{\mathrm{o}}}{V_{\text {in }}}=\left(\frac{1}{1-k}\right)
\end{aligned}
$$

Let $k$ be the duty cycle for SLCPOBC and let it be 0.6 in this study. Input voltage applied to SLCPOBC is $12 \mathrm{~V}$ DC. Consider the converter is operating in CCM. The output voltage $V_{\mathrm{o}} \&$ voltage transfer gain $\mathrm{G}$ can be obtained from Eq. (1).

$$
\begin{aligned}
& V_{\mathrm{o}}=\frac{1}{(1-0.6)} \cdot 12=29.26 \mathrm{~V} \\
& G=\frac{29.2}{12}=2.43
\end{aligned}
$$

\subsection{Two Level Cascaded Positive Output Boost Converter}

Two level cascaded positive output boost converter was designed by adding inductor $L_{2}$, diodes $D_{2}$ and $D_{3}$ and capacitor $C_{2}$ to single level converter. In this study, TLCPOBC was selected for the investigation. Fig. 2 illustrates the power circuit of TLCPOBC.

Power circuit incorporates switch $S$, two inductors $L_{1}$, $L_{2}$, two capacitors $C_{1}, C_{2}$, three power diodes $D_{1}, D_{2}$, and $D_{3}$ and load resistance $R$. When switch $S$ is closed, the input voltage $V_{\text {in }}$ appears across inductor $L_{1}$ and capacitor voltage $V_{C 1}$ appears across inductor $L_{2}$. Now, the inductor current $i_{L 2}$ increases with capacitor voltage $V_{C 1}$. Simillarly, when switch $\mathrm{S}$ is opened, the inductor current $i_{L 2}$ declines with $\left(V_{C 1}-V_{\mathrm{o}}\right)$ and the capacitor voltage becomes $V_{C 2}=V_{\mathrm{o}}$.

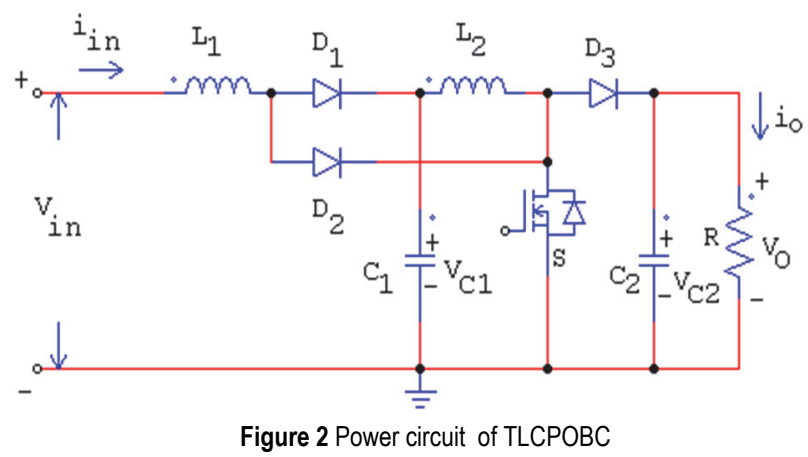

Therefore, the output voltage $\left(V_{\mathrm{o}}\right)$ and output voltage transfer gain of TLCPOBC can be written as Eq. (3):

$$
\begin{aligned}
& V_{\mathrm{o}}=\frac{1}{(1-k)} V_{1}=\left(\frac{1}{1-k}\right)^{2} V_{\text {in }} \\
& G=\frac{V_{\mathrm{o}}}{V_{\text {in }}}=\left(\frac{1}{1-k}\right)^{2}
\end{aligned}
$$

\subsection{Design of Power Circuit Components for TLCPOBC}

In this section, power circuit components such as inductors $L_{1}, L_{2}$, capacitors $C_{1}, C_{2}$, output voltage $V_{\text {o }}$, output power $\left(P_{\mathrm{o}}\right)$ and efficiency for TLCPOBC was calculated. Let $k$ be the duty cycle for TLCPOBC and let it be 0.6 in this study. Input voltage applied to TLCPOBC is $12 \mathrm{~V}$ DC. The converter operates in CCM. The output voltage $V_{\mathrm{o}} \&$ voltage transfer gain $G$ can be obtained from Eq. (6):

$$
\begin{aligned}
& V_{\mathrm{o}}=\frac{1}{(1-0.6)} \cdot 12=75 \mathrm{~V} \\
& G=\frac{V_{\mathrm{o}}}{V_{\text {in }}}=\left(\frac{75}{12}\right)=6.25
\end{aligned}
$$

With the help of $V_{\mathrm{o}}$ and load resistance $R$, the output current $i_{\mathrm{o}}$ (mean value) can be calculated from Eq. (5):

$i_{\mathrm{o}}=\frac{V_{0}}{R}=\frac{75}{50}=1.5 \mathrm{~A}$

Output power $P_{\mathrm{o}}$ can be calculated with the help of output voltage $V_{\mathrm{o}} \&$ output current $\left(I_{\mathrm{o}}\right)$ by using the Eq. (6):

$$
\begin{aligned}
& P_{\mathrm{o}}=V_{\mathrm{o}} I_{\mathrm{o}} \\
& P_{\mathrm{o}}=75 \cdot 1.5 \\
& P_{\mathrm{o}}=112.5 \mathrm{~W}
\end{aligned}
$$

Let the maximum efficiency of the converter be $85 \%$ in this study. With the help of $P_{\mathrm{o}}$ and efficiency, the input power $P_{\text {in }}$ can be calculated from Eq. (7):

$$
\begin{aligned}
& \eta=85 \% \\
& P_{\text {in }}=P_{\mathrm{o}} / \eta \\
& P_{\text {in }}=112.5 / 0.85 \\
& P_{\text {in }}=132 \mathrm{~W}
\end{aligned}
$$


From obtained values of input power \& input voltage, Input current $I_{\text {in }}$ was found from the Eq. (8):

$I_{\text {in }}=\frac{P_{\text {in }}}{V_{\text {in }}}=\frac{132}{12}=11 \mathrm{~A}$

Inductors $L_{1}$ and $L_{2}$ values were obtained by considering $\Delta i_{L 1}=0.16 \mathrm{~A}$. Similarly the capacitor values $C_{1}$ and $C_{2}$ were obtained by considering $\Delta V_{\mathrm{o}}=0.5 \mathrm{~V}$.

$$
\begin{aligned}
& L_{1}=L_{2}=\frac{V_{\text {in }}}{f_{s} \Delta i_{L 1}} k, L_{1}=L_{2}=\frac{12}{100 \mathrm{e}^{3} \cdot 0.16} \cdot 0.593, \\
& L_{1}=445 \mu \mathrm{H} \\
& C_{1}=\frac{(1-k) V_{\mathrm{o}}}{f_{s} \Delta V_{\mathrm{o}} R}, C_{1}=\frac{(1-0.916) \cdot 75}{100 \mathrm{e}^{3} \cdot 0.5 \cdot 50}=12 \mu \mathrm{F} \\
& \xi=\frac{\Delta v_{o} / 2}{V_{\mathrm{o}}}=\frac{(1-k)}{2 R f_{s} C_{2}}, \\
& C_{2}=\frac{k V_{c 1}}{(1-k)^{2} f_{s} \Delta V_{\mathrm{o}} R}=16.5 \mu \mathrm{F}
\end{aligned}
$$

\begin{tabular}{|c|c|c|}
\hline Parameters name & Symbol & Value \\
\hline Input Voltage & $V_{\text {in }}$ & $12 \mathrm{~V}$ \\
\hline Output Voltage & $V_{\mathrm{o}}$ & $75 \mathrm{~V}$ \\
\hline Inductors & $L_{1}, L_{2}$ & $445 \mu \mathrm{H}$ \\
\hline Capacitors & $C_{1}, C_{2}$ & $\begin{array}{l}12 \mu \mathrm{F}, \\
16.5 \mu \mathrm{F}\end{array}$ \\
\hline $\begin{array}{l}\text { Nominal switching } \\
\text { frequency }\end{array}$ & $f_{s}$ & $100 \mathrm{kHz}$ \\
\hline Load resistance & $R$ & $50 \Omega$ \\
\hline Output power & $P_{\mathrm{o}}$ & $112.5 \mathrm{~W}$ \\
\hline Input power & $P_{\text {in }}$ & $132 \mathrm{~W}$ \\
\hline Average input current & $I_{\text {in }}$ & $11 \mathrm{~A}$ \\
\hline Efficiency & $\eta$ & $85 \%$ \\
\hline Average output current & $i_{\mathrm{o}}$ & $1.5 \mathrm{~A}$ \\
\hline Duty ratio & $K$ & 0.6 \\
\hline $\begin{array}{l}\text { Peak to Peak Inductor } \\
\text { Current Ripple }\end{array}$ & $\Delta_{L 1}$ & $25 \%$ of $I_{\text {in }}$ \\
\hline $\begin{array}{c}\text { Peak to Peak Output } \\
\text { Capacitor Ripple } \\
\text { Voltage }\end{array}$ & $\Delta V_{\mathrm{o}}$ & $0.5 \mathrm{~V}$ \\
\hline
\end{tabular}

Tabe 1 Specifications of the TLCPOBC

\section{STATE SPACE AVERAGE MODELLING OF TLCPOBC}

Considering the merits and need of multi-level converters, TLCPOBC was designed with the help of state space averaging model. When Switch $S$ is closed, refer to Fig. 2, the state space equations of TLCPOBC can be written as Eq. (10)

$$
\left\{\begin{array}{l}
\frac{\mathrm{d} i_{L 1}}{\mathrm{~d} t}=\frac{V_{\text {in }}}{L_{1}} \\
\frac{\mathrm{d} i_{L 2}}{\mathrm{~d} t}=\frac{V_{C 1}}{L_{2}} \\
\frac{\mathrm{d} V_{C 1}}{\mathrm{~d} t}=-\frac{i_{L 2}}{C_{1}} \\
\frac{\mathrm{d} V_{\mathrm{o}}}{\mathrm{d} t}=-\frac{V_{\mathrm{o}}}{C_{2} R}
\end{array}\right.
$$

Similarly, when switch $S$ is opened, the state space equations can be written as Eq. (11):

$$
\left\{\begin{array}{l}
\frac{\mathrm{d} i_{L 1}}{\mathrm{~d} t}=\frac{V_{\text {in }}-V_{C 1}}{L_{1}}(1-k) \\
\frac{\mathrm{d} i_{L 2}}{\mathrm{~d} t}=\frac{V_{C 1}-V_{\mathrm{o}}}{L_{2}}(1-k) \\
\frac{\mathrm{d} V_{C 1}}{\mathrm{~d} t}=\frac{i_{L 1}-i_{L 2}}{C_{1}}(1-k) \\
\frac{\mathrm{d} V_{\mathrm{o}}}{\mathrm{d} t}=\frac{i_{L 2}-\frac{V_{\mathrm{o}}}{R}}{C_{2}}(1-k)
\end{array}\right.
$$

From Eq. (10) \& Eq. (11), we can obtain complete state space averaging model of TLCPOBC as shown in Eq. (12):

$$
\begin{aligned}
& {\left[\begin{array}{c}
\frac{\mathrm{d} i_{L 1}}{\mathrm{~d} t} \\
\frac{\mathrm{d} i_{L 2}}{\mathrm{~d} t} \\
\frac{\mathrm{d} V_{C 1}}{\mathrm{~d} t} \\
\frac{\mathrm{d} V_{C o}}{\mathrm{~d} t}
\end{array}\right]=\left[\begin{array}{lll}
0 & 0 & \frac{(1-k)}{L_{1}} \\
0 & 0 & \frac{1}{L_{1}} \\
\frac{(1-k)}{C_{1}} & \frac{1}{C_{1}} & 0 \\
0 & \frac{(1-k)}{C_{2}} & 0
\end{array}\right.} \\
& Y=\left[\begin{array}{llll}
0 & 0 & 0 & 1
\end{array}\right]\left[\begin{array}{l}
i_{L 1} \\
i_{L 2} \\
V_{C 1} \\
V_{0}
\end{array}\right]
\end{aligned}
$$$$
\left.\begin{array}{c}
0 \\
\frac{(1-k)}{L_{1}} \\
0 \\
\frac{1}{C_{2} R}
\end{array}\right]\left[\begin{array}{l}
i_{L 1} \\
i_{L 2} \\
V_{C 1} \\
V_{\mathrm{o}}
\end{array}\right]+\left[\begin{array}{l}
\frac{1}{L_{1}} \\
0 \\
0 \\
0
\end{array}\right] V_{\text {in }}
$$

Calculated values in chapter 3 were substituted in state space average Eq. (12). Now, the matrices $A, B, C$ and $D$ of TLCPOBC become as shown in Eq. (13):

$$
\begin{aligned}
& A=\left[\begin{array}{lccc}
0 & 0 & -914 & 0 \\
0 & 0 & 2247 & -914 \\
33917 & -83333 & 0 & 0 \\
0 & 24667 & 0 & -1212
\end{array}\right], \\
& B=\left[\begin{array}{l}
2247 \\
0 \\
0 \\
0
\end{array}\right], C=\left[\begin{array}{llll}
0 & 0 & 0 & 1
\end{array}\right], D=\left[\begin{array}{lll}
0 & 0 & 0
\end{array}\right]
\end{aligned}
$$

\section{NEED OF MULTI LEVEL CONVERTERS}

In current scenario, the role of solar energy is very much needed for many applications such as solar powered vehicles, solar powered water pumping etc., However, the output from solar cell is very low and it has to be boosted with the help of DC-DC boost converter to meet the application requirements. The boosting capability of the converter can be achieved by increasing the values of power circuit components such as inductor \& capacitor. However, increasing their values may lead to larger ripples in the output voltage. In addition, the circuit leads to electromagnetic interference. To overcome these issues, 
multi-level DC-DC boost converters were implemented. Hence in this article, both single level and two level converter have been taken into consideration.

Table 2 Output voltage and Voltage transfer gain of SLCPOBC \& TLCPOBC for

\begin{tabular}{|c|l|c|c|c|c|}
\multicolumn{2}{|c|}{ Duty ratio $k$} & 0.2 & 0.4 & 0.6 & 0.8 \\
\hline \multirow{2}{*}{ SLCPOBC } & $V_{\mathrm{o}}$ & $15 \mathrm{~V}$ & $20 \mathrm{~V}$ & $30 \mathrm{~V}$ & $60 \mathrm{~V}$ \\
\cline { 2 - 6 } & $G$ & 1.25 & 1.66 & 2.5 & 5 \\
\hline \multirow{2}{*}{ TLCPOBC } & $V_{\mathrm{o}}$ & $18 \mathrm{~V}$ & $33 \mathrm{~V}$ & $75 \mathrm{~V}$ & $300 \mathrm{~V}$ \\
\cline { 2 - 6 } & $G$ & 1.5 & 2.75 & 6.25 & 25 \\
\hline
\end{tabular}

Tab. 2 shows the importance and need of multi-level converters in DC-DC applications. The output voltage $V_{\mathrm{o}}$ and voltage transfer gain $G$ for both SLCPOBC and TLCPOBC under various duty ratio have been calculated. Assume the input voltage applied to the converter is $12 \mathrm{~V}$ DC. For duty ratio $k=0.8$, the output voltage of TLCPOBC was $300 \mathrm{~V}$ with voltage transfer gain around 25. Whereas, in SLCPOBC the output voltage is only $60 \mathrm{~V}$ with voltage transfer gain around 5 which is almost 5 times less than TLCPOBC. Hence, from the comparison it is clearly observed and concluded that the performance of TLCPOBC is better than SLCPOBC which has better voltage transfer gain. In addition, the output voltage increases rapidly with increase in duty ratio.

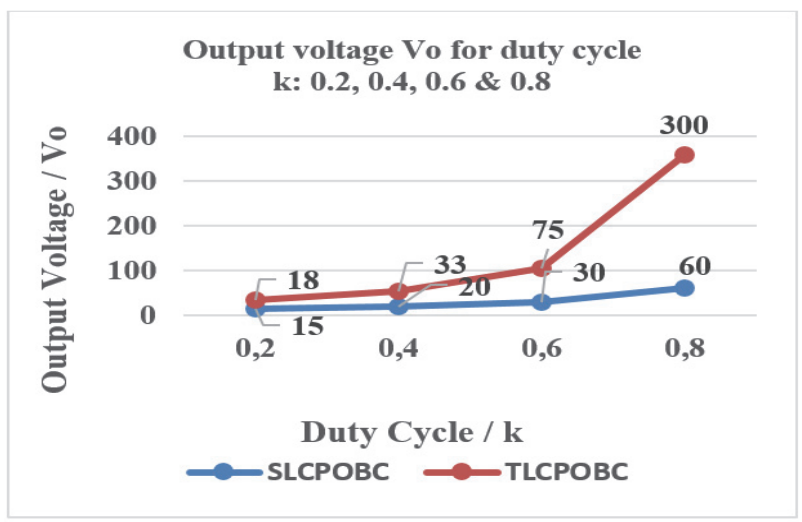

(a)

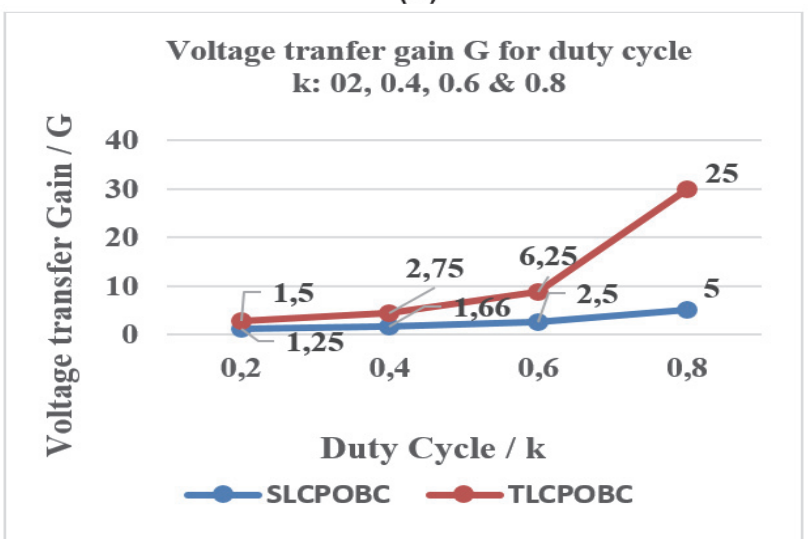

(b)

Figure 3 Performance comparison of SLCPOBC \& TLCPOBC (a) Output voltage and Duty ratio (b) Voltage transfer gain and duty ratio

Tab. 3 shows the output voltage $\left(V_{\mathrm{o}}\right)$ for change in Input voltage $\left(V_{\text {in }}\right)$. From the table it is clear that the output voltage of TLCPOBC is compartively larger than SLCPOBC of the same input voltage.
Table 3 Output voltage of SLCPOBC \& TLCPOBC for change in Input Voltage

\begin{tabular}{|c|c|c|c|c|c|}
\hline \multicolumn{7}{|c|}{ Duty ratio $k: 0.6$} \\
\hline \multicolumn{2}{|c|}{ Input Voltage $V_{\text {in }}$} & $12 \mathrm{~V}$ & $15 \mathrm{~V}$ & $20 \mathrm{~V}$ & $25 \mathrm{~V}$ \\
\hline SLCPOBC & $V_{\mathrm{o}}$ & $30 \mathrm{~V}$ & $37.5 \mathrm{~V}$ & $50 \mathrm{~V}$ & $62.5 \mathrm{~V}$ \\
\hline TLCPOBC & $V_{\mathrm{o}}$ & $75 \mathrm{~V}$ & $93.7 \mathrm{~V}$ & $125 \mathrm{~V}$ & $156.2 \mathrm{~V}$ \\
\hline
\end{tabular}

Output Volatge response for change in Input voltage

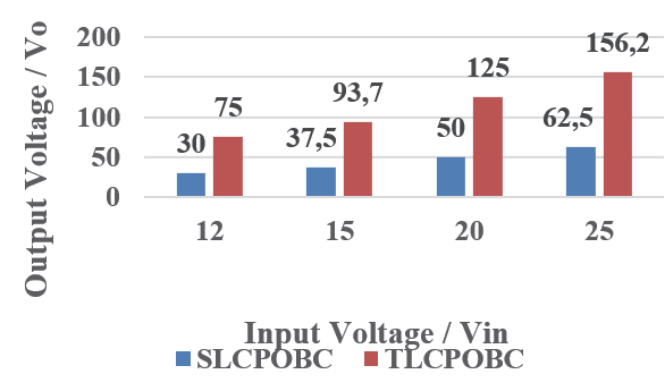

Figure 4 Output voltage response for change in Input voltage with duty ratio 0.6

Therefore it is clear that multilevel boost converter plays a major role in DC-DC application for increasing the output voltage without increasing the number of switches in the power circuit. The simulation of single level and two level cascaded positive output boost converter was performed in MATLAB/Simulink platform and the results were validated to show the importance of multilevel boost converter in DC to DC application.

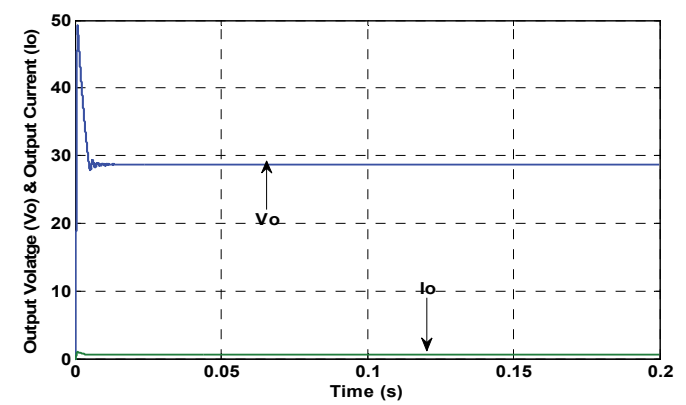

(a)

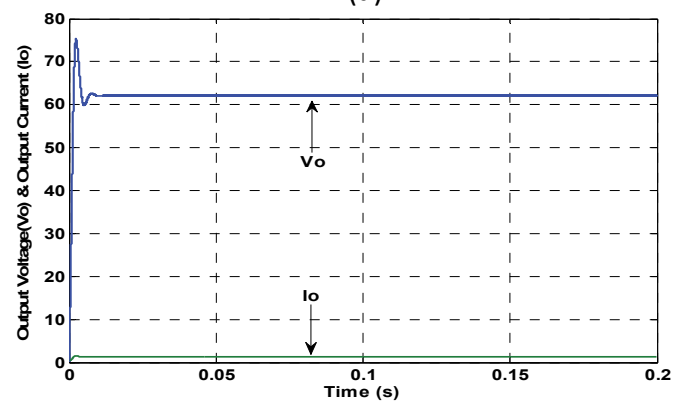

(b)

Figure 5 Output voltage and output current response (a) SLCPOBC (b) TLCPOBC - Simulation

Fig. 5 shows the simulated output voltage $\left(V_{\mathrm{o}}\right)$ for 12 $\mathrm{V}$ input. From the output it is clear that output voltage of TLCPOBC is almost double the time compared with SLCPOBC. The simulation was carried out in open loop system which has produced peak overshoots of $20.3 \mathrm{~V}$ in 
SLCPOBC and $12.9 \mathrm{~V}$ in TLCPOBC during the start-up region. Therefore, effective controllers were required to nullify this issue.

\section{CONTROLLER DESIGN FOR TLCPOBC}

In this section, the controller design for TLCPOBC has been discussed elaborately. The main intention of this article is to develop an effective controller for TLCPOBC with least disturbance under various operating conditions. TLCPOBC was implemented with the help of PI and P plus PI. Here, PI acts as single loop controller (SLC) and P plus PI acts as multi loop controller (MLC).

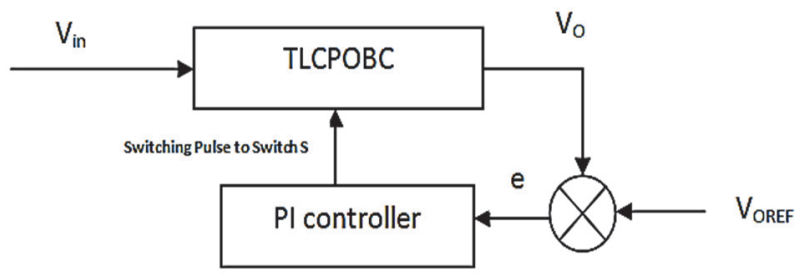

(a)

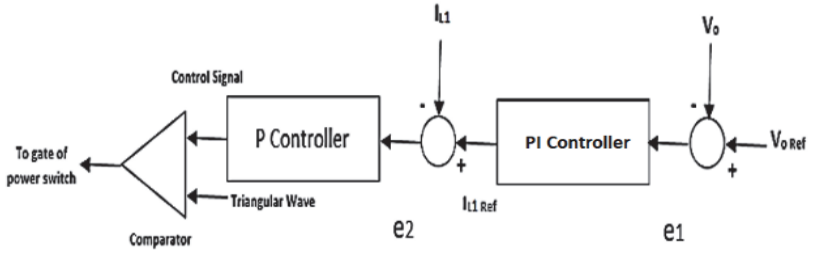

(b)

Figure 6. Block diagram of Single loop \& Multi loop controller for TLCPOBC (a) $\mathrm{PI}$ controller (b) P plus PI

Fig. 6a, shows the block diagram of single loop controller using PI for TLCPOBC. The output voltage $V_{\mathrm{o}}$ from converter is compared with reference output voltage $V_{\text {oRef }}$ which generates error signal e. This error signal e is applied to PI controller. The output from PI controller drives the Switch $S$ of TLCPOBC. In this controller, inductor current was not taken into consideration. Due to this, the converter has produced oscillation in the output voltage $\left(V_{\mathrm{o}}\right)$ which has been discussed in chapter 4 . To overcome this issue and to operate the converter in stable condition, multi loop controller was suggested. In MLC, both output voltage and inductor current of TLCPOBC were considered which improves the performance of the system over wide range of operating conditions.

Fig. 6b shows the multi loop controllers using $\mathrm{P}$ plus PI for TLCPOBC. Here, PI acts as outer loop voltage controller and $\mathrm{P}$ acts as inner loop current controller. The output voltage $V_{\mathrm{o}}$ from converter is compared with reference output voltage $V_{\text {oRef }}$ which generates error signal $e_{1}$. This error signal $e_{1}$ is applied to the outer loop voltage controller PI. The controller PI generates reference inductor current $i_{L 1 \text { ref. }}$ This reference inductor current $i_{L 1 \text { ref }}$ is compared with inductor current $i_{L 1}$ from power circuit of TLCPOBC which generates error signal $e_{2}$. Now, this error signal $e 2$ is applied to inner current controller P. Finally the control signal from $\mathrm{P}$ controller is compared with triangular wave which drives the main switch $S$ of TLCPOBC.

With the help of Zeigler-Nichols tuning procedure, the parameters of PI and P plus PI such as proportional gain $\left(K_{\mathrm{p}}\right)$ and integral times $\left(T_{i} \mathrm{~s}\right)$ were determined.
From the Eq. (13), the transfer function $G(s)$ for TLCPOBC is obtained as shown in Eq. (14).

$$
G(s)=\frac{4.224 \mathrm{e}^{15}}{s^{4}+1212 s^{3}+2.182 \mathrm{e}^{8} s^{2}+2.645 \mathrm{e}^{11} s-2.192 e^{-22}}
$$

One of the denominator values from Eq. (14) is very small $2.192 \mathrm{e}^{-22}$. Hence, it can be omitted. Now, the Eq. (14) becomes:

$$
G(s)=\frac{4.224 \mathrm{e}^{15}}{s^{4}+1212 s^{3}+2.182 \mathrm{e}^{8} s^{2}+2.645 \mathrm{e}^{11} s}
$$

Eq. (16) shows the characteristic equation of proportional control for TLCPOBC:

$$
s^{4}+1212 s^{3}+2.182 \mathrm{e}^{8} s^{2}+2.645 \mathrm{e}^{11} s+K 4.224 \mathrm{e}^{15}=0
$$

Ultimate gain with sustained oscillation for TLCPOBC was achieved using this technique. With the help of RouthHurwitz condition $\left(K_{c r}=0.0034\right)$ and its matching ultimate period $\left(P_{c r}=0.000012 \mathrm{~s}\right)$, the stability was found. Based on trial-error approach, the parameters such as proportional gain and integral time were found. The proportional gain $K_{p}=K_{c r} / 2=0.0017$ and its integral time $T_{i}=P_{c r} / 1.2=$ $0.000011 \mathrm{~s}$ were determined by trial-error methods.

\section{SIMULATION RESULTS}

The main purpose of this research work is to verify the operating conditions of TLCPOBC using SLC \& MLC. Due to switching mode operation, the characteristics of TLCPOBC were non-linear in nature. Hence, the validation of TLCPOBC was performed for different operating conditions such as Line variations, Load variations, circuit component variations and ripple voltage analysis. Simulation results of controller PI and P plus PI were analysed and compared.

\subsection{Line Variation}

The input voltage for TLCPOBC is varied from $12 \mathrm{~V}$ to $15 \mathrm{~V}$ at $0.1 \mathrm{~s}$. Fig. $7 \mathrm{a} \&$ Fig. $7 \mathrm{~b}$ show the simulated output voltage of PI and P plus PI controllers. From the result it is found that the output of SLC has produced both increased \& decreased overshoots of $16 \mathrm{~V} \& 7 \mathrm{~V}$ with settling time of $0.02 \mathrm{~s}$. Whereas, in MLC it has only increased overshoot of $12 \mathrm{~V}$ with settling time of $0.01 \mathrm{~s}$. In addition, it is clearly found that MLC had not produced any oscillations during the transient period.

Similarly, the input voltage is varied from $15 \mathrm{~V}$ to 12 $\mathrm{V}$ at 0.1 s. Fig. $8 \mathrm{a} \&$ Fig. 8 b shows the simulated output voltage of PI and P plus PI controllers. From the result it is found that the output of SLC has produced both increased $\&$ decreased overshoots of $6 \mathrm{~V} \& 12 \mathrm{~V}$ with settling time of $0.02 \mathrm{~s}$. Whereas in MLC it has only decreased overshoot of $10 \mathrm{~V}$ with settling time of $0.01 \mathrm{~s}$. In addition, it is clearly found that MLC has not produced any oscillations during the transient period. 


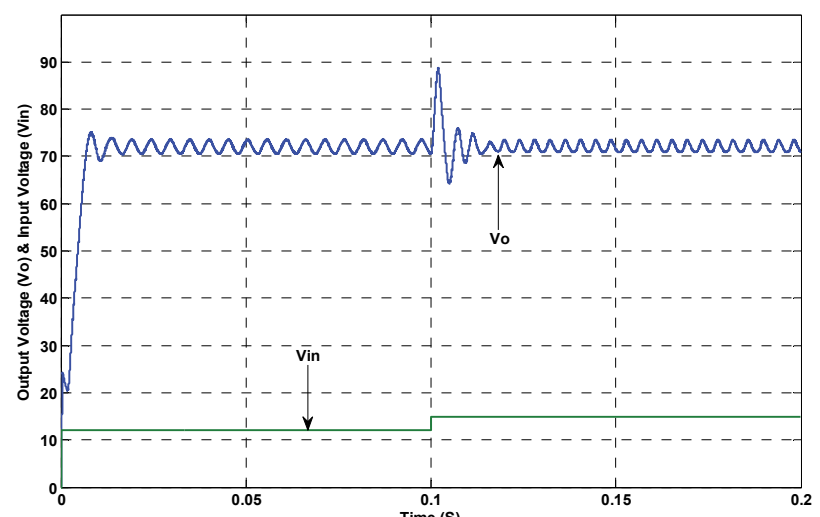

(a)

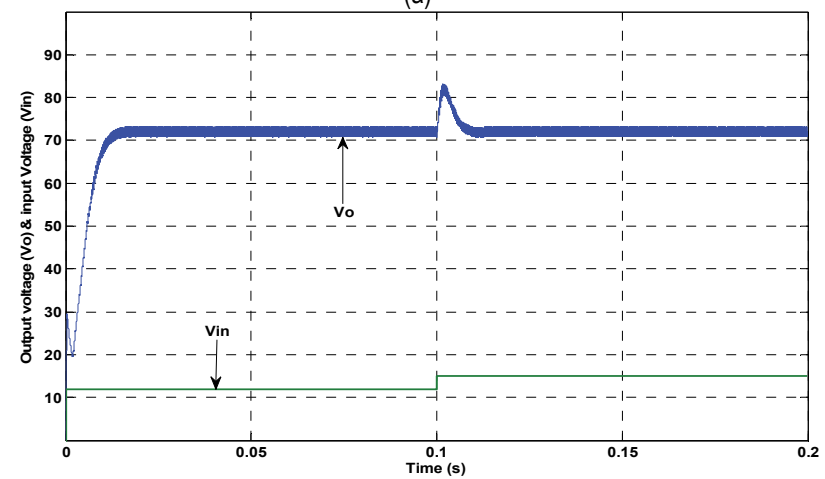

(b)

Figure 7 Output voltage response for change in input voltage from $12 \mathrm{~V}$ to 15 $\mathrm{V}$ (a) PI \& (b) P plus PI - Simulation

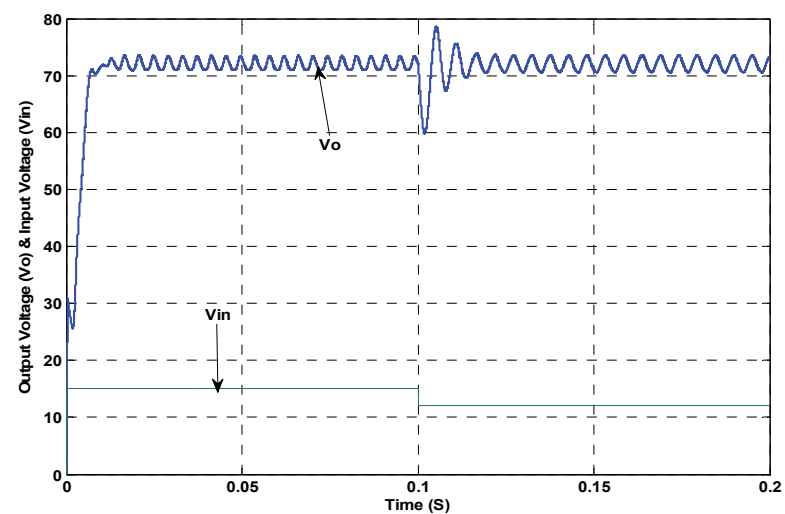

(a)

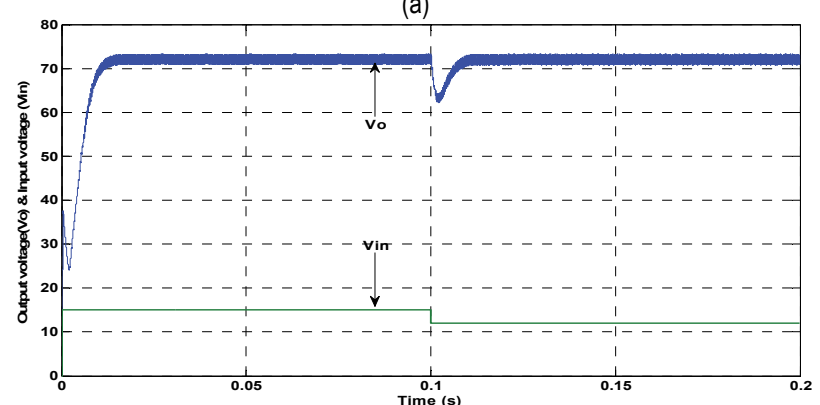

(b)

Figure 8 Output voltage response for change in input voltage from $15 \mathrm{~V}$ to $12 \mathrm{~V}$ (a) PI \& (b) P plus PI - Simulation

\subsection{Load Variation}

The load resistance of TLCPOBC is varied from 50 ohm to $40 \Omega$ at 0.1 s. Fig. 9 a $\&$ Fig. 9 b show the simulated output voltage and current responses of PI \& P plus PI. From the result it is found that the output of SLC has produced both increased \&decreased overshoots of $3 \mathrm{~V} \&$
$4 \mathrm{~V}$ with settling time of $0.02 \mathrm{~s}$. Whereas in MLC it has only decreased overshoot of $3 \mathrm{~V}$ with settling time of 0.01 $\mathrm{s}$. In addition, it is clearly found that MLC has not produced any oscillations during the transient period.

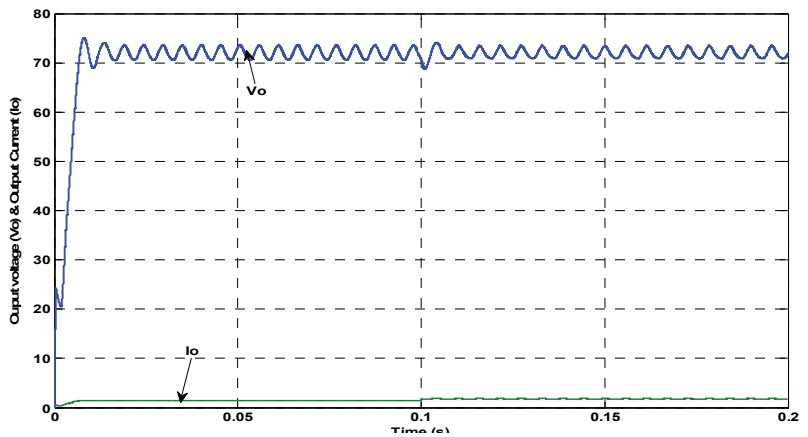

(a)

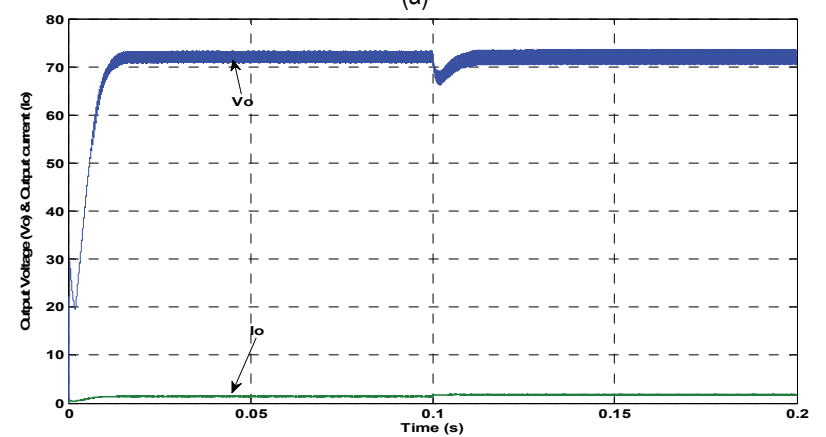

(b)

Figure 9. Output voltage and current response for change in load resistance from $50 \Omega$ to $40 \Omega$. (a) PI \& (b) P plus PI - Simulation

Similarly, the load resistance is varied from $50 \Omega$ to 60 $\Omega$ at 0.1 s. Fig. $10 \mathrm{a} \&$ Fig. $10 \mathrm{~b}$ show the simulated output voltage using PI and P plus PI. From the result it is found that the output of SLC has produced increased overshoots of $6 \mathrm{~V}$ with settling time of $0.04 \mathrm{~s}$. Whereas in MLC it has only increased overshoot of $4 \mathrm{~V}$ with settling time of 0.01 s. In addition, it is clearly found that MLC has not produced any oscillations during the transient period.

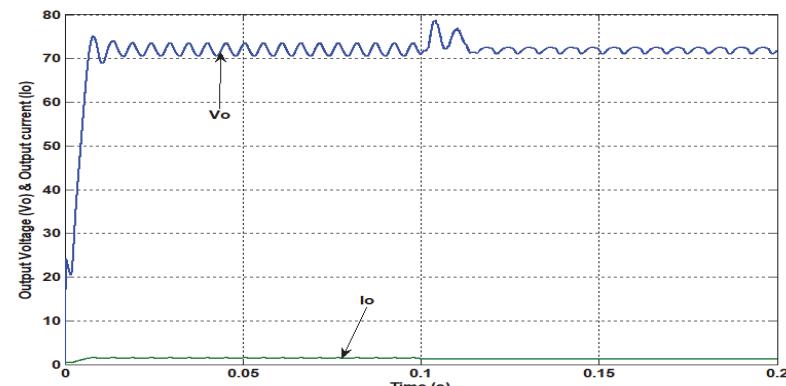

(a)

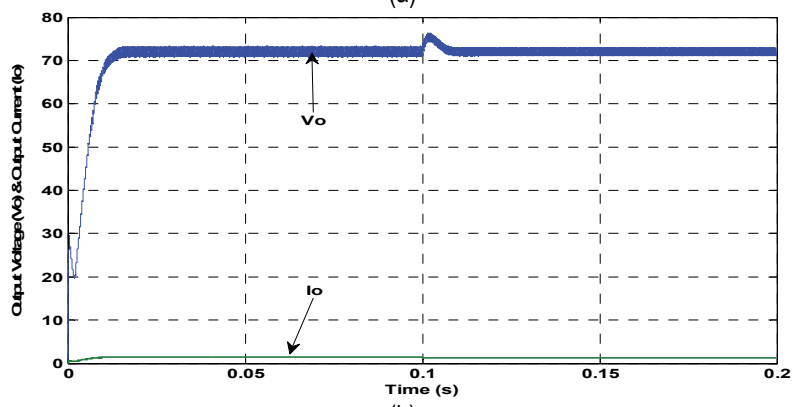

(b)

Figure 10. Output voltage and current response for change in load resistance from $50 \Omega$ to $60 \Omega$. (a) PI \& (b) P plus PI - Simulation 


\subsection{Circuit Component Variations and Ripple Voltage Analysis}

The simulated output voltage responses of TLCPOBC for change in capacitor value from $16.5 \mu \mathrm{F}$ to $20 \mu \mathrm{F}$ and change in inductance value from $445 \mu \mathrm{H}$ to $500 \mu \mathrm{H}$ using PI \& P plus PI were shown in Fig. 11a \& Fig. 11b. The simulated output result shows that output voltage of TLCPOBC using PI controller (SLC) has larger ripples which was around 3.1 V. However, using P plus PI (MLC) the ripples in the output voltage have been reduced considerably and it was only around $1 \mathrm{~V}$.

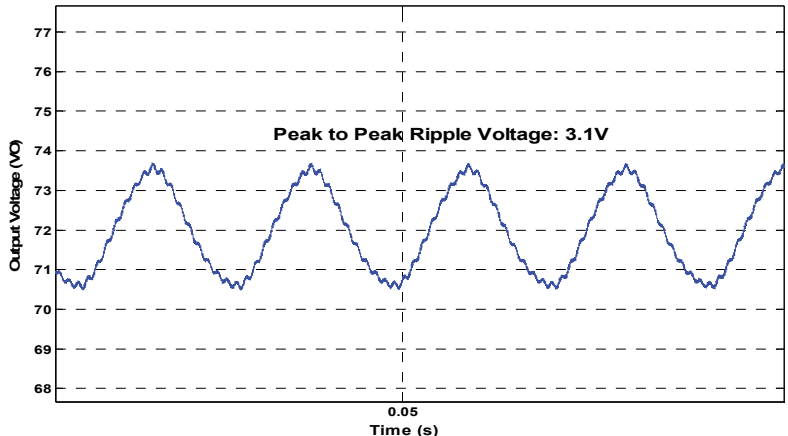

(a)

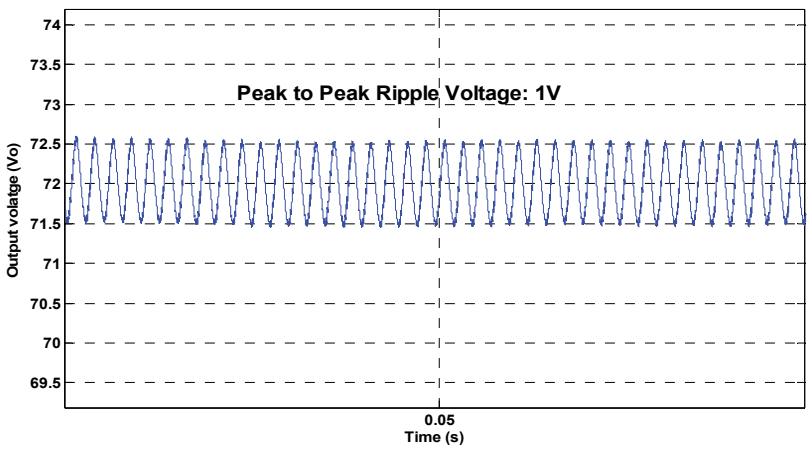

(b)

Figure 11. Peak to Peak ripple output voltage for change in capacitor value from $16.5 \mu \mathrm{F}$ to $20 \mu \mathrm{F}$. (a) PI \& (b) P plus PI-Simulation

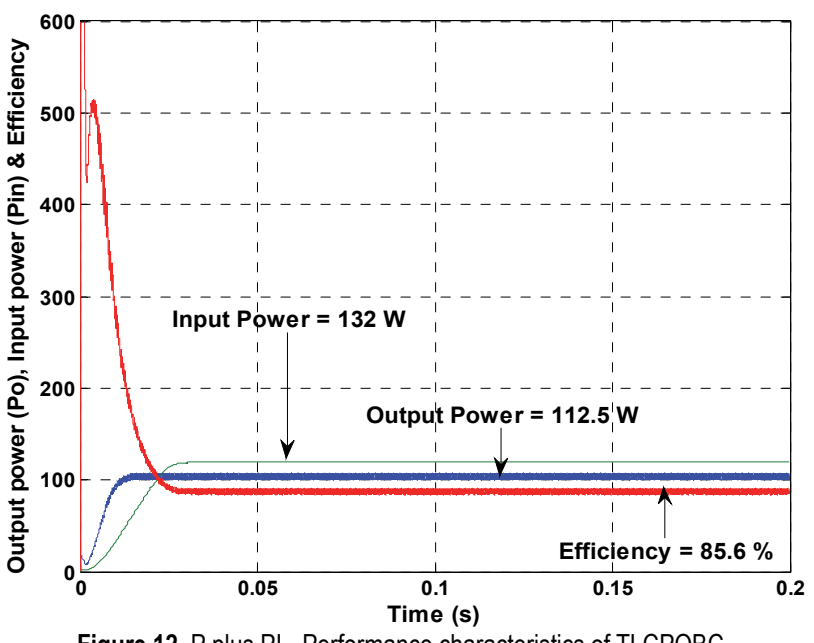

Figure 12. P plus PI - Performance characteristics of TLCPOBC

From the simulation results and comparison table, it is clearly found that multi loop controller (MLC) P plus PI enhances the dynamic characteristics of TLCPOBC in comparison with single loop controller (SLC) PI. The PI controller has produced increased and decreased overshoots in the output during the line variation with prolonged oscillations in the output voltage. However, using P plus PI the oscillations were eliminated and also the controller has produced least overshoot during the input voltage variations. Similarly, during the load variations the output voltage of PI controller has significant overshoots. But in the case of P plus PI, the overshoot and settling time were greatly reduced. In addition, the peak to peak output voltage ripple using PI controller is high around $3.1 \mathrm{~V}$. Whereas, in P plus PI the output voltage ripple was around $1 \mathrm{~V}$. Hence, by considering the merits it is concluded that Multi loop controllers (P plus PI) are best suitable for TLCPOBC compared with single loop controller (PI) for $\mathrm{DC}$ to DC applications.

Table 4 Comparison of SLC \& MLC under different operating conditions

\begin{tabular}{|c|c|c|c|c|}
\hline \multirow{2}{*}{$\begin{array}{l}\text { Operating } \\
\text { conditions }\end{array}$} & \multicolumn{2}{|c|}{$\begin{array}{l}\text { PI Controller } \\
\text { (SLC) }\end{array}$} & \multicolumn{2}{|c|}{$\begin{array}{l}\text { P plus PI Controller } \\
\text { (MLC) }\end{array}$} \\
\hline & PI & $\begin{array}{l}\text { Settling } \\
\text { time }\end{array}$ & $\mathrm{P}$ plus $\mathrm{PI}$ & $\begin{array}{l}\text { Settling } \\
\text { time }\end{array}$ \\
\hline $\begin{array}{l}\text { Input voltage } \\
12 \mathrm{~V} \text { to } 15 \mathrm{~V}\end{array}$ & $\begin{array}{c}16 \mathrm{~V} \\
\text { (Increase) } \\
7 \mathrm{~V} \text { (Decrease) } \\
\text { Has } \\
\text { oscillations }\end{array}$ & $0.02 \mathrm{~s}$ & $\begin{array}{c}12 \mathrm{~V} \\
\text { (Increase) } \\
\text { No } \\
\text { oscillations }\end{array}$ & $0.01 \mathrm{~s}$ \\
\hline $\begin{array}{l}\text { Input voltage } \\
15 \mathrm{~V} \text { to } 12 \mathrm{~V}\end{array}$ & $\begin{array}{c}6 \mathrm{~V} \text { (Increase) } \\
12 \mathrm{~V} \\
\text { (Decrease) } \\
\text { Has } \\
\text { oscillations }\end{array}$ & $0.02 \mathrm{~s}$ & $\begin{array}{c}10 \mathrm{~V} \\
\text { (Decrease) } \\
\text { No } \\
\text { oscillations }\end{array}$ & $0.02 \mathrm{~s}$ \\
\hline $\begin{array}{c}\text { Load } \\
\text { Resistance } \\
50 \Omega \text { to } 40 \Omega\end{array}$ & $\begin{array}{c}3 \mathrm{~V} \text { (Increase) } \\
4 \mathrm{~V} \text { (Decrease) } \\
\text { Has } \\
\text { oscillations }\end{array}$ & $0.02 \mathrm{~s}$ & $\begin{array}{c}3 \mathrm{~V} \\
\text { (Decrease) } \\
\text { No } \\
\text { oscillations }\end{array}$ & $0.02 \mathrm{~s}$ \\
\hline $\begin{array}{c}\text { Load } \\
\text { Resistance } 50 \\
\Omega \text { to } 60 \Omega\end{array}$ & $6 \mathrm{~V}$ (Increase) & $0.04 \mathrm{~s}$ & $4 \mathrm{~V}$ (Increase) & $0.01 \mathrm{~s}$ \\
\hline $\begin{array}{c}\text { Peak to Peak } \\
\text { ripple voltage } \\
\text { for } 16.5 \mu \mathrm{F} \text { to } \\
20 \mu \mathrm{F} \\
\text { capacitor } \\
\text { change }\end{array}$ & $3.1 \mathrm{~V}$ & - & $1 \mathrm{~V}$ & - \\
\hline
\end{tabular}

\section{CONCLUSIONS}

In this article, the design and performance analysis of effective controller for Multi-level cascaded positive output boost converter operating in CCM has been attempted successfully in MATLAB/Simulink platform. Cascaded DC to DC boost converter accomplishes better voltage transfer gain and increased output voltage with simple structure. The obtained values of voltage transfer gain show the importance and need of TLCPOBC. To enhance the dynamic behavior of the converter, multi loop controller has been developed. The simulation was carried out for different operating conditions using single loop controller and multi loop controller for TLCPOBC. Further the results of both the controllers were compared to validate the importance and need of effective controller for TLCPOBC. From the comparison it is clear that the designed multi loop controller P plus PI has excellent dynamic characteristics in all operating conditions. During the line \& load variations, the MLC has produced least overshoots compared with SLC. In addition, the peak to peak output voltage ripples were less, around $1 \mathrm{~V}$. Hence, 
the designed Multi loop controller is best suitable for TLCPOBC of medium \& high power applications.

\section{REFERENCES}

[1] Marchesoni, M. \& Vacca, C. (2007). New DC-DC Converter for Energy Storage System Interfacing in Fuel Cell Hybrid Electric Vehicles. IEEE Trans Power Electron., 22(1), 301-286. https://doi.org/10.1109/TPEL.2006.886650

[2] Napoli, A. D., Crescimbini, F., \& Rodo, S. (2002). Multiple input $\mathrm{dc} / \mathrm{dc}$ converter for fuel-cell powered hybrid vehicles. IEEE Power Electron. Spec. Conf. (PESC),1685-1690. https://doi.org/10.1109/PSEC.2002.1023053

[3] Wuhua, L., Yi, Z., Yan, D., \& Xiangning, H. (2010). Interleaved Converter with Voltage Multiplier Cell for High step-up and High efficiency Conversion. IEEE Trans. Power Electron., 25(9), 2397-2408. https://doi.org/10.1109/TPEL.2010.2048340

[4] Shih-Ming, C., Tsorng-Juu, L., Lung-Sheng, Y., \& JiannFuh, C. (2011). A Cascaded High Step-Up DC-DC Converter with Single Switch for Microsource Applications. IEEE Trans. Power Electron., 26(4), 1146-1153. https://doi.org/10.1109/TPEL.2010.2090362

[5] Ahmad Saudi, S., Taufiq, A. J. S., \& Abdul, H. M. Y. (2011). Simulation and Implementation of Interleaved Boost DC-DC Converter for Fuel Cell Application. International Journal of Power Electronics and Drive Systems., 1(2), 168-174. https://doi.org/10.11591/ijpeds.v1i2.126

[6] Chiu, H. J., Huang, H. M., Lin, L. W., \& Tseng, M. H. (2005). A multipleinput DC/DC converter for renewable energy system. Proc. IEEE Int. Conf. Ind. Technol., 13041308. https://doi.org/10.1109/ICIT.2005.1600837

[7] Miao, Z. \& Fang, L. L. (2007). Implementing of developed volatge lift technique on SPEIC, Cuk and Double-output DC-Dc Converters. Second IEEE Conference on Industrial Electronics and Applications, 674-681. https://doi.org/10.1109/ICIEA.2007.4318492

[8] Masahito, J., Po-Yuan, C., Yu-Chun, L., \& Koosuke, H. (2010). Investigation on the ripple voltage and the stability of SR Buck converters with high output voltage current and low output voltage. IEEE Transactions On Industrial Electronics, 57(3), 1008-1016. https://doi.org/10.1109/TIE.2009.2029510

[9] Jorge, A. M. S., Roberto, G. Q., \& Jesus, L. R. (2006). Modeling and control of a cascaded boost converter with single switch. IEEE Transactions, 591-596. https://doi.org/10.1109/IECON.2006.347554

[10] Fang, L. L. \& Hong, Y. (2014). Advanced DC/DC converters. CRC Press, London.

[11] Franciso, J. P. P. \& Ilse, C. (2009). Multi-objective Control for Cascade Boost Converter with Single Active Switch. IEEE Proceedings, 1858-1862. https://doi.org/10.1109/IEMDC.2009.5075456

[12] Luo, F. L. \& Ye, H. (2004). Positive output cascade boost converters. IEE Proc.-Electr. Power Appl., 151(5), 590-606. https://doi.org/10.1049/ip-epa:20040511

[13] Davood, G. \& Mehmet, C. (2017). Implementaion of PI Cascaded Boost Power Converters in Parallel Connection with High Efficiency. Journal of Electrical System, 13(2), 307-321.

[14] Kanimozhi, G., Meenakshi, J., \& Sreedevi, V. T. (2017). Small signal modeling of a DC-DC type Double Boost Converter Integrated with SEPIC Converter using state space Averaging Approach. Energy Procedia, 117, 835-846. https://doi.org/10.1016/j.egypro.2017.05.201

[15] Pavan, K. M. S. V. \& Yuri, B. S. (2016). Robust Sliding Mode Control Design for a Quadratic Boost Converter.
International Journal of Electronics and Electrical Engineering, 4(5), 386-391.

https://doi.org/10.18178/ijeee.4.5.386-391

[16] Sivakumar, A. \& Premalatha, L. (2018). Modified Sliding mode control of Non Ideal Case Voltage boost converter. International Journal of Pure and Applied Mathematics, 119(17), 753-766.

[17] Ayhan, O. \& Zekiye, E. (2017). Double-loop PI controller design of the DC-DC converter with a proposed approach for calculation of the controller parameters. Journal of Systems and Control Engineering, 1-12. https://doi.org/10.1177/0959651817740006

[18] Ahmed, A. \& Hafez, A. (2015). Multi-level cascaded DC/DC converters for PV applications. Alexandria Engineering Journal, 55(4), 1135-1146. https://doi.org/10.1016/j.aej.2015.09.004

[19] Zeynep, B. D., Hanifi, G., \& Servet, T. (2018). Fuzzy Sliding mode control of DC-DC boost converter. Journal of Engineering, Technology \& Applied Research, 8(3), 30543059. https://doi.org/10.48084/etasr.2116

\section{Contact information:}

Saktheeswaran RADHAKRISHNAN, Ph.D., Associate Professor (Corresponding author)

Department of Electrical \& Electronics Engineering,

Roever College of Engineering and Technology,

Elambalur, Tamil Nadu 621220 - India

E-mail: sakthir.tcs@gmail.com

Murali DURAISAMY, Ph.D., Professor

Department of Electrical \& Electronics Engineering,

Government College of Engineering,

Salem, Tamil Nadu 636011 - India

E-mail: muralid36@yahoo.com 